\title{
EFFECT OF THE SEMI-ELLIPTIC SPRING MOUNTING ON ITS STIFFNESS
}

\author{
Mariusz STAŃCO ${ }^{1}$, Paulina DZIALAK ${ }^{2}$
}

1 University of Science and Technology, Faculty of Mechanical Engineering, Department of Machine Design and Research, Łukasiewicza 5, 50-371 Wroclaw, Poland, e-mail: mariusz.stanco@ @wr.edu.pl

2 University of Science and Technology, Faculty of Mechanical Engineering, Department of Machine Design and Research, Łukasiewicza 5, 50-371 Wroclaw, Poland, e-mail: paulina.dzialak@pwr.edu.pl

\section{Introduction}

Properly selected stiffness of heavy duty vehicles suspension affects the driver and passenger comfort by reducing or increasing the level of vibrations caused by the unevenness of the road. The stiffness of the suspension should be adjusted in such a way that the frame of the vehicle overcoming the given obstacle does not move with the suspension in vertical direction. The energy generated as a result of driving through the road unevenness should mostly be absorbed by the suspension. The stiffness of the suspension in turn depends on the spring stiffness and torsional stiffness of the stabilizer. Therefore, the correct selection of the spring stiffness is extremely important.

In trucks where the traditional suspension based on leaf springs is applied, semi-elliptical springs are rarely used due to their high weight. In military vehicles semi-elliptical springs is a basic component of the front axle suspension (Fig. 1), and in many vehicles of the tandem type suspension (Fig. 2). Both types of springs are connected in their middle part with the vehicle axle by screw or with the tandem axle cradle by U-bolts $[1,4]$ interconnected by a clip (Fig. 3).

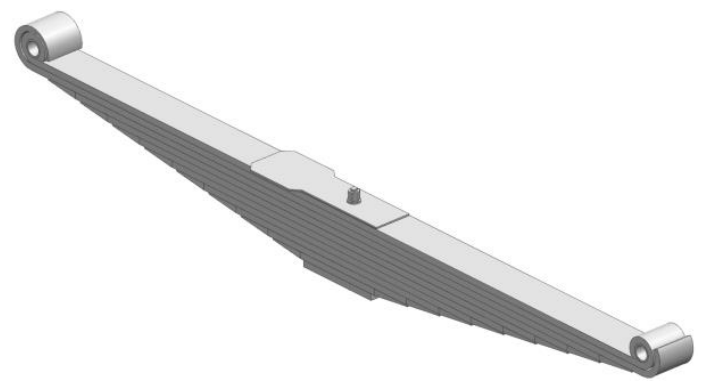

Fig. 1. Semi-elliptical spring of the front axle.

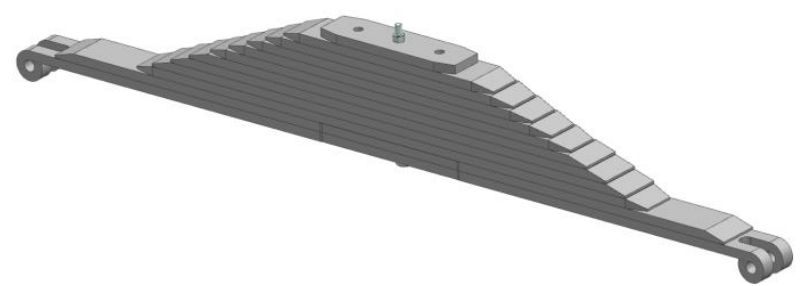

Fig. 2. Tandem type semi-elliptical spring.

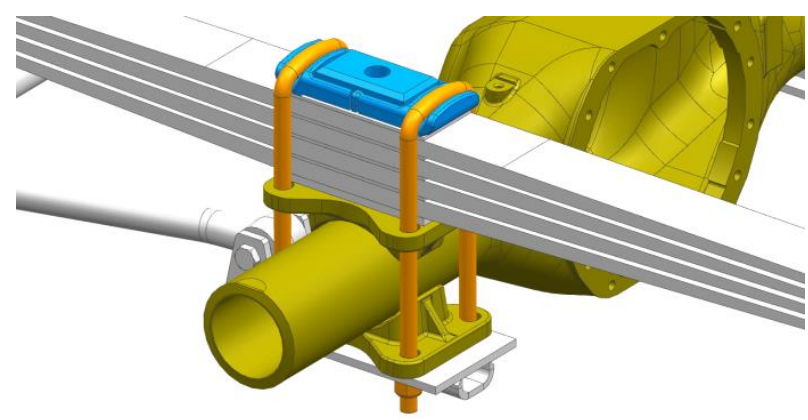

Fig. 3. Mounting of the spring on the vehicle axle.

\section{Experimental studies}

The measurements of spring deflection and the deflection force were performed. On their basis spring stiffness characteristics were determined. The measurements were made for a semi-elliptic spring with a length of $1600 \mathrm{~mm}$ consisting of nine leaves [2]. Measurements were made on one spring in two different variants:

- spring fastened by a central screw (Fig. 4a),

- spring clamped with the U-bolts tightened with the required torque (Fig. 4b).

The second variant of the spring represents the actual spring mounting on the truck during its operation. 
a)

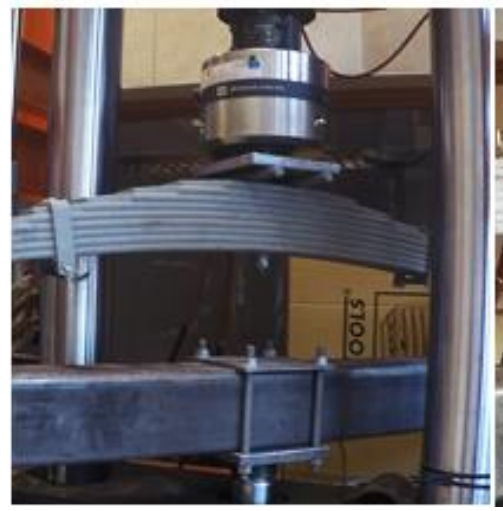

b)

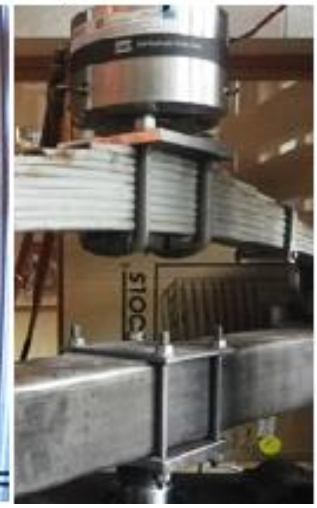

Fig. 4. Semi-elliptical spring; a - fastened with central screw, $\mathrm{b}$ - connected with U-bolts.

Hysteresis loops for both versions of the spring were determined based on the conducted tests (Figures 5, 6). The stiffness of both springs was also obtained in compliance with current standards [3].

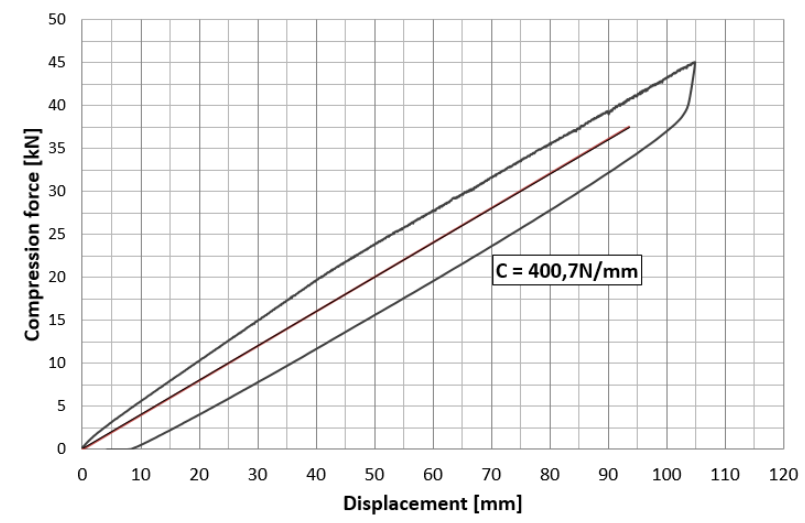

Fig. 5. Hysteresis loop obtained during the compression of the spring fastened with the clamp.

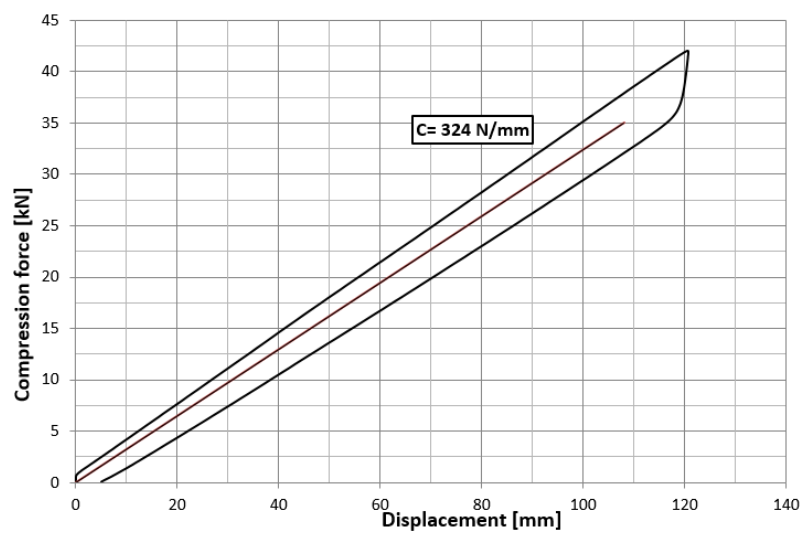

Fig. 6. Hysteresis loop obtained during the compression of the spring fastened with the central screw.

The studies of the spring stiffness with mounting similar to the one on the actual vehicle frame is $23 \%$ higher than the stiffness of the spring tested according to the guidelines recommended by the standard. This results from the fact that the leaf springs fastened with the clip in the central part are stiffened and are not allowed to work freely. The distance between the U-bolts is about $160 \mathrm{~mm}$. This reduce the active length of the spring by $10 \%$.

The hysteresis loops of both springs also differ from each other (Fig. 7). In the spring connected with U-bolts, significant influence of the friction may be noticed. It generates strain, contributing to increased wear of the leaves.

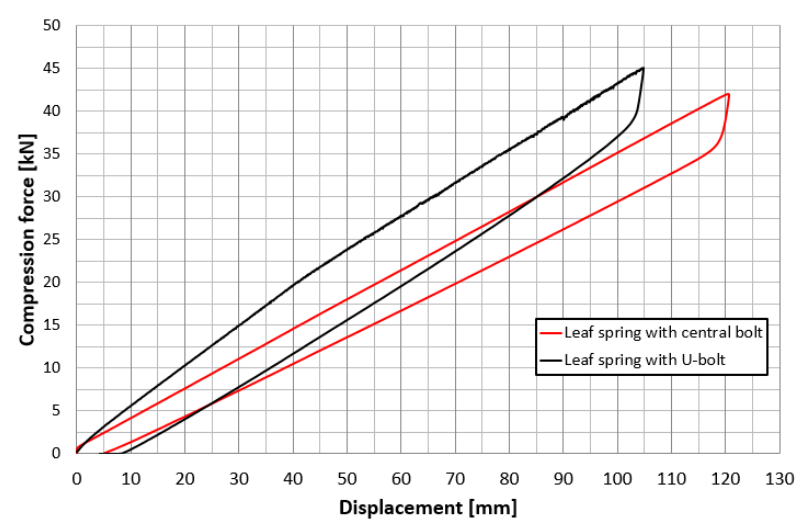

Fig. 7. Hysteresis loops of both springs.

\section{Conclusions}

Presented results of the experimental studies conducted on the semi-elliptical spring indicated that in the process of a new leaf spring selection it is necessary to take into consideration the mounting on the axle. In the analysed case, the actual stiffness of the spring was $23 \%$ higher than the stiffness determined on the basis of the recognised standard.

\section{References}

[1] Stańco M., Działak P., Hejduk M.: Failure analysis of a damaged U-bolt top plate in a leaf spring. Proceedings of the 14th International Scientific Conference: Computer Aided Engineering, 2019, 736-743

[2] Stańco M., Iluk A., Działak P., Numerical and experimental analysis of stress of a semi-elliptical spring. Materials Today: Proceedings, 5 (13), Part 2, 2018, 26760-26765

[3] PN-S-47250:1990: Pojazdy samochodowe i przyczepy - Resory piórowe - Wymagania i badania

[4] SAE, Spring Design Manual - Design and Application of Leaf Springs, HS-744, AE-11,90, SAE International, 1990. 